Jurnal Qua Teknika, Vol. 9 No. 1 Maret 2019

ISSN 2088-2424 (cetak); ISSN 2527-3892 (elektronik)

Fakultas Teknik Universitas Islam Balitar, Blitar

Https://ejournal.unisbablitar.ac.id/index.php/qua; Email: quateknika@unisbablitar.ac.id

Nila Nurlina. 2019. Pengaruh Pengujian Hardening pada Baja Karbon Rendah Sebagai Solusi Peningkatan Kualitas Material.

Jurnal Qua Teknika, (2019), 9(1) : 11-20

\title{
PENGARUH PENGUJIAN HARDENING \\ PADA BAJA KARBON RENDAH SEBAGAI SOLUSI PENINGKATAN KUALITAS MATERIAL
}

\author{
Nila Nurlina \\ Program Studi Perawatan dan Perbaikan Mesin, Politeknik Kediri \\ Jl. Mayor Bismo No 27, Kota Kediri \\ email: nila24.ppm@gmail.com
}

\begin{abstract}
ABSTRAK
Baja karbon rendah merupakan paduan yang terdiri atas unsur utama karbon dengan komposisi rendah dan besi. Sifat mekanik baja karbon rendah dipengaruhi oleh komposisi dan struktur mikro logam. Salah sifat mekanik logam yang akan dicari nilainya adalah kekerasan. Tujuan penelitian ini adalah melakukan pengujian hardening terhadap material baja karbon rendah. Hasil yang didapatkan dari penelitian ini yaitu nilai kekerasan baja karbon rendah semakin meningkat seiring bertambahnya suhu pemanasan. Selain itu, berdasarkan data hasil percobaan diketahui bahwa media pendingin air garam memiliki kekerasan lebih tinggi dibandingkan dengan oli SAE 10.
\end{abstract}

Kata kunci: Baja. Hardening, kekerasan.

\section{PENDAHULUAN}

\section{Latar Belakang}

Perkembangan ilmu material semakin pesat seiring dengan kemajuan teknologi yang ada di dunia ini. Perkembangan ilmu material juga diiringi dengan kompleksitas kebutuhan manusia. Beranekaragam komposit dan paduan dibuat menyesuaikan fungsi dan tujuan yang ingin didapatkan. Salah satu paduan yang sering diaplikasikan dalam pembuatan produk adalah baja karbon rendah. Baja karbon rendah merupakan paduan yang terdiri atas unsur utama karbon dengan komposisi rendah dan besi. Dewasa ini banyak industri mengaplikasikan pembentukan lembaran baja yang memiliki berkekuatan tinggi. Hal tersebut tidak mudah dilakukan karena dipengaruhi oleh sifat bahan dimana kekuatan baja selalu disertai dengan penurunan elongasi (Sari, 2017).

Sifat-sifat logam, khususnya sifat mekanik logam, sangat dipengaruhi oleh komposisinya dan struktur mikro logam. Salah satu sifat mekanik logam yang ingin diketahui nilainya adalah kekerasan (hardness). Kekerasan material harus diketahui apabila akan diaplikasikan sebagai material yang akan menerima gaya gesek maupun tekan. Setiap material akan mengalami deformasi plastis dengan tingkatan yang berbeda-beda tergantung pada kompsisi penyusunya. Oleh karena itu, sebelum material tersebut diaplikasikan, harus diuji terlebih dahulu untuk mendapatkan sifat-sifat yang sesuai.

Sementara, sifat-sifat logam bisa dibentuk dengan merekayasa struktur mikro logam melalui perlakuan panas. Hal tersebut dapat dilakukan dengan perlakuan panas (heat treatment) yang salah satunya yaitu pengujian hardening. Tujuan perlakuan panas ini adalah untuk mengubah struktur pada logam. Perlakuan panas adalah proses kombinasi antara proses pemanasan dan pendinginan suatu logam dalam keadaan padat pada temperatur rekristalisasi kemudian dilakukan penahan suhu dan pendinginan. Media pendingin yang biasa digunakan dalam pengujian kekerasan hardening adalah oli dan air garam.

Tujuan penelitian ini adalah melakukan pengujian hardening terhadap material baja karbon rendah sebagai solusi peningkatan kualitas material. Hasil perlakuan material dengan hardening selanjutnya akan diuji nilai kekerasan dengan rockwell test. Selain itu, setelah mendapatkan perlakuan, spesimen juga diuji ketangguhannya dengan pengujian impact. Variabel dalam penelitian ini yaitu suhu dan media pendingin. Suhu pada perlakuan ini dibuat secara bervariasi yaitu dari $700{ }^{\circ} \mathrm{C}$ dan meningkat sampai dengan $880{ }^{\circ} \mathrm{C}$. Pengujian hardening ini memiliki waktu tahan selama 15 menit. Sementara variabel lainnya dalam penelitian ini yaitu media pendingin. Media pendingin yang digunakan dalam penelitian ini berupa oli dan air garam.

Hasil yang didapatkan dari penelitian ini yaitu nilai kekerasan baja karbon rendah semakin meningkat seiring bertambahnya suhu pemanasan. Selain itu, berdasarkan data hasil percobaan diketahui bahwa media pendingin air garam memiliki kekerasan lebih tinggi dibandingkan dengan oli SAE 10. 
Jurnal Qua Teknika, Vol. 9 No. 1 Maret 2019

ISSN 2088-2424 (cetak); ISSN 2527-3892 (elektronik)

Fakultas Teknik Universitas Islam Balitar, Blitar

Https://ejournal.unisbablitar.ac.id/index.php/qua; Email: quateknika@unisbablitar.ac.id

Nila Nurlina. 2019. Pengaruh Pengujian Hardening pada Baja Karbon Rendah Sebagai Solusi Peningkatan Kualitas Material.

Jurnal Qua Teknika, (2019), 9(1) : 11-20

\section{Diagram Fase Besi-Karbon (Fe-C)}

Diagram fase besi karbida besi merupakan suatu diagram perlakuan panas yang digunakan sebagai panduan dalam melakukan pengujian. Dalam diagaram tersebut terlihat sifat-sifat material yang berbeda. Sifat-sifat material tersebut dipengaruhi oleh suhu yang diberikan dan komposisi paduan.

Prosentasi penambahan karbon akan menyebabkan sifat material menjadi lebih keras daripada sebelumnya. Secara teori, paduan besi dan karbon dapat membentuk paduan besi dan baja. Sifat logam yang terbentuk berdasarkan diagram tersebut adalah sifat liquid, austenit, ferit, besi delta, serta sementit.

\section{Perlakuan Panas (Heat Treatment)}

Heat Treatment ( perlakuan panas ) adalah proses yang memiliki tujuan mengubah struktur logam dengan cara memanaskan spesimen uji hingga mencapai suhu tertentu pada dapur furnace (tanur). Pemanasan ini dilakukan pada temperatur rekristalisasi yang dimiliki oleh masing-masing logam. Selanjutnya, spesimen uji didinginkan pada media pendingin seperti udara, air, air garam, oli dan solar dimana setiap media pendingin tersebut memiliki tingkat kerapatan pendinginan yang berbeda-beda. Sifat-sifat logam terutama sifat mekanik selain dipengaruhi oleh komposisi penyusunnya juga sangat dipengaruhi oleh struktur mikrologam. Suatu logam atau paduan akan mempunyai sifat mekanis yang berbeda-beda apabila struktur mikronya dirubah.

Pemberian perlakuan pemanasan atau pendinginan dengan kecepatan yang tidak sama tersebut mengakibatkan logam dan paduan merubah strukturnya. Pengubahan struktur logam dapat dilakukan dengan perlakuan panas. Pencapaian sifat material logam yang sesuai kebutuhan manusia tersebut dapat dilakukan dengan mengatur kecepatan proses pendinginan dan batas temperatur yang digunakan selama pengujian.

\section{- Macam-macam Perlakuan}

1. Normalizing

2. Hardening

3. Carburizing

- Waktu tahan

1. 15 menit (Normalizing)

2. 15 menit (Hardening)

3. 3 jam (Carburizing)

\section{- Media Pendingin}
1. Udara
(Normalizing)
2. Oli dan Garam
(Hardening)
3. Udara
(Carburizing)

\section{Hardening}

Hardening merupakan proses pemanasan logam sampai suhu di atas daerah kritis. Pada proses hardening ini pendinginan dilakukan secara cepat dengan media pendingin seperti oli, dan air garam. Tujuan perlakuan panas ini untuk mendapatkan struktur baja martensit yang memiliki sifat keras. Proses pada perlakuan panas ini adalah dengan cara memanaskan baja sampai suhu martensit. Penentuan suhu tersebut dipengaruhi oleh komposisi penyusun paduan. Selanjutnya, proses penahan suhu beberapa saat sesuai dengan standar. Setelah proses pemanasan dan penahanan suhu, kemudian didinginkan secara cepat dengan mencelupkan dalam media pendingin berupa air garam, air, oli atau media pendingin yang lain. Pendinginan cepat tersebut mengakibatkan struktur austenit tidak memiliki cukup waktu untuk berubah menjadi perlit dan ferit atau perlit dan sementit. Pendinginan cepat ini mengakibatkan austenit langsung berubah menjadi martensit. 
Jurnal Qua Teknika, Vol. 9 No. 1 Maret 2019

ISSN 2088-2424 (cetak); ISSN 2527-3892 (elektronik)

Fakultas Teknik Universitas Islam Balitar, Blitar

Https://ejournal.unisbablitar.ac.id/index.php/qua; Email: quateknika@unisbablitar.ac.id

Nila Nurlina. 2019. Pengaruh Pengujian Hardening pada Baja Karbon Rendah Sebagai Solusi Peningkatan Kualitas Material.

Jurnal Qua Teknika, (2019), 9(1) : 11-20

Suhu perlakuan panas dengan hardening ini berbeda-beda sesuai dengan jenis komposisinya yang tebagi menjadi baja hipoeutectoid, eutektoid, dan hypereutectoid. Baja hipoeutectoid membutuhkan suhu pemanasan sekitar $30-50^{\circ} \mathrm{C}$ di atas titik atas temperatur kritis. Disisi lain, baja hypereutectoid membutuhkan suhu pemanasan sekitar $30-50^{\circ} \mathrm{C}$ di atas titik atas temperatur kritis.

Penahanan suhu pada baja berdasarkan proses ini tergantung pada ketebalan spesimen uji yang kemudian didinginnkan secara cepat. Struktur baja hypoeutectoid terdiri dari struktur ferrit dan pearlit. Sementara, struktur baja hypereutectoid terdiri dari pearlit dan cementit.

\section{Rockwell (HR / RHN)}

Pengujian kekerasan dengan metode Rockwell bertujuan melihat nilai kekerasan material. Pengujian ini merupakan pengujian kekerasan yang menggunakan alat bantu mesin rockwell. Indentor yang digunakan pada pengujian ini berupa bola baja ataupun kerucut intan. Indentor tersebut ditekankan pada permukaan material uji.

Mekanisme pengujian kekerasan dengan rockwell yaitu pertama benda uji ditekan oleh indetor bola baja maupun kerucut intan dengan beban dan ditahan beberapa saat untuk mendapatkan nilai kekerasan materialnya. Besar beban yang digunakan untuk menekan indentor ke benda uji tergantung pada jenis material yang akan diujikan.

\section{METODE PENELITIAN}

\section{Material}

1. Baja karbon rendah 8 buah

$\begin{array}{ll}\text { Alat dan Bahan } & \\ \text { 1. Furnace } & 2 \text { unit } \\ \text { 2. Rockwell } & 2 \text { unit } \\ \text { 3. Gergaji } & 1 \text { buah } \\ \text { 4. Kikir } & 1 \text { buah } \\ \text { 5. Amplas } & \text { secukupnya } \\ \text { 6. Stopwatch } & 1 \text { buah } \\ \text { 7. Tang } & 1 \text { buah } \\ \text { 8. Sarung tangan kulit } & 1 \text { set }\end{array}$

\section{Prosedur Percobaan}

Langkah-langkah pengujian yang dilakukan pada penelitian ini adalah sebagai berikut:

1. Memanaskan spesimen hingga temperatur $\mathrm{T} 1$ yakni $\left(880^{\circ} \mathrm{C}, 850^{\circ} \mathrm{C}, 820^{\circ} \mathrm{C}, 750^{\circ} \mathrm{C}, 700^{\circ} \mathrm{C}\right)$.

2. Melakukan waktu tahan yaitu selama 15 menit untuk masing-masing proses.

3. Melakukan pendinginan dengan media air garam dan oil.

4. Pengujian kekerasan

5. Catat data hasil pengujian 
Jurnal Qua Teknika, Vol. 9 No. 1 Maret 2019

ISSN 2088-2424 (cetak); ISSN 2527-3892 (elektronik)

Fakultas Teknik Universitas Islam Balitar, Blitar

Https://ejournal.unisbablitar.ac.id/index.php/qua; Email: quateknika@ unisbablitar.ac.id

Nila Nurlina. 2019. Pengaruh Pengujian Hardening pada Baja Karbon Rendah Sebagai Solusi Peningkatan Kualitas Material.

Jurnal Qua Teknika, (2019), 9(1) : 11-20

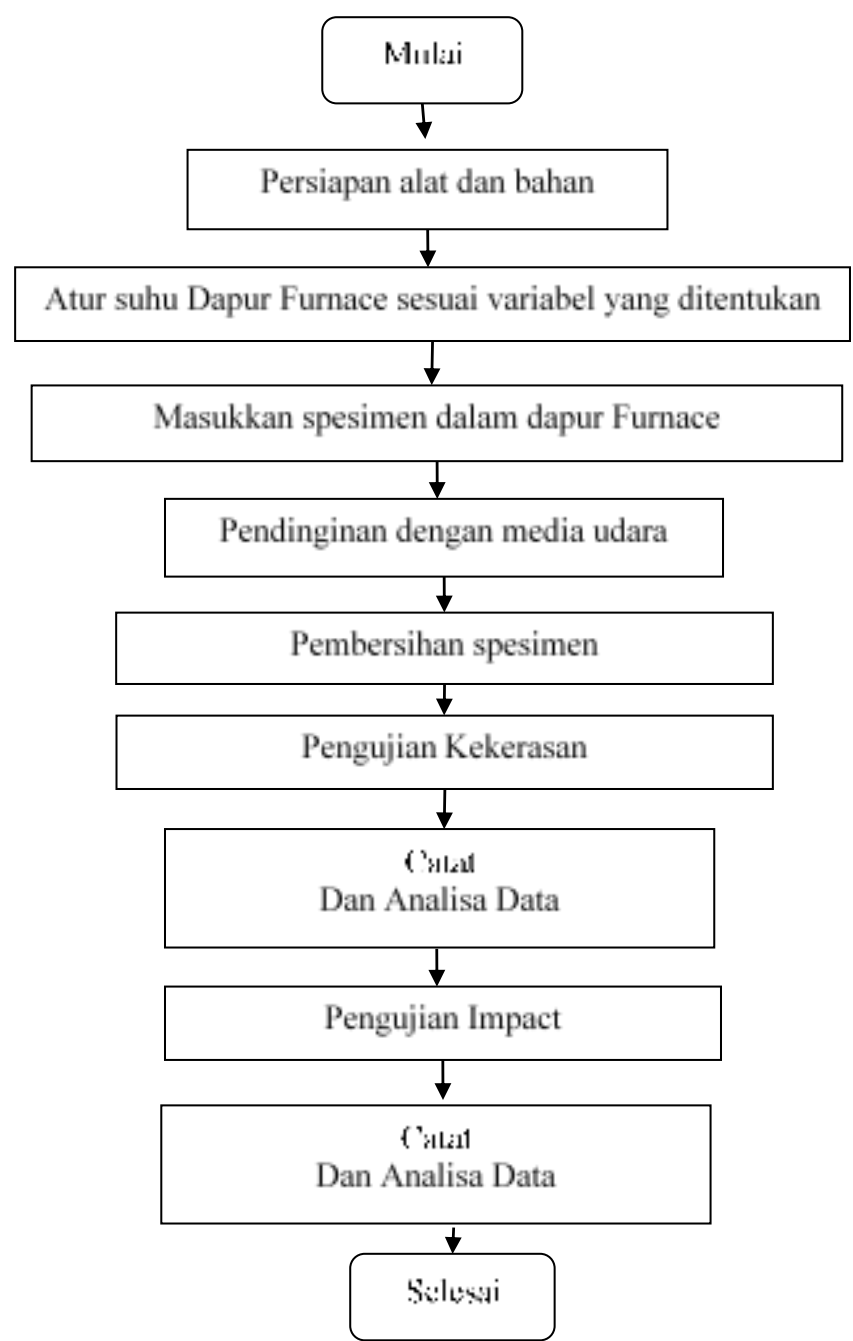

Gambar 1. Langkah-langkah Pengujian

\section{Skema Percobaan}

Skema percobaan dalam penelitian ini yaitu dengan metode eksperimen. Adapun langkah-langkah percobaan yang dilakukan pertama dengan pembuatan spesimen uji, pemanasan dengan dapur furnace (tanur), penahanan suhu pada spesimen uji, dan pendinginan cepat.

1. Pembuataan spesimen

Material spesimen uji pada penelitian ini adalah baja karbon rendah yang biasa terdapat di pasaran. Baja tersebut dipotong sesuai dengan spesifikasi yang telah ditentukan derdasarkan ASTM material. Berikut merupakan gambaran umum pembuatan spesimen uji.

Pembuatan spesimen dengan bantuan alat kikir dan ragum sebagai penahan spesimen. Pembuatan spesimen ini memerlukan ketrampilan kikir agar spesimen yang dihasilkan bisa presisi sesuai dengan yang telah distandarkan. 
Jurnal Qua Teknika, Vol. 9 No. 1 Maret 2019

ISSN 2088-2424 (cetak); ISSN 2527-3892 (elektronik)

Fakultas Teknik Universitas Islam Balitar, Blitar

Https://ejournal.unisbablitar.ac.id/index.php/qua; Email: quateknika@ unisbablitar.ac.id

Nila Nurlina. 2019. Pengaruh Pengujian Hardening pada Baja Karbon Rendah Sebagai Solusi Peningkatan Kualitas Material.

Jurnal Qua Teknika, (2019), 9(1) : 11-20

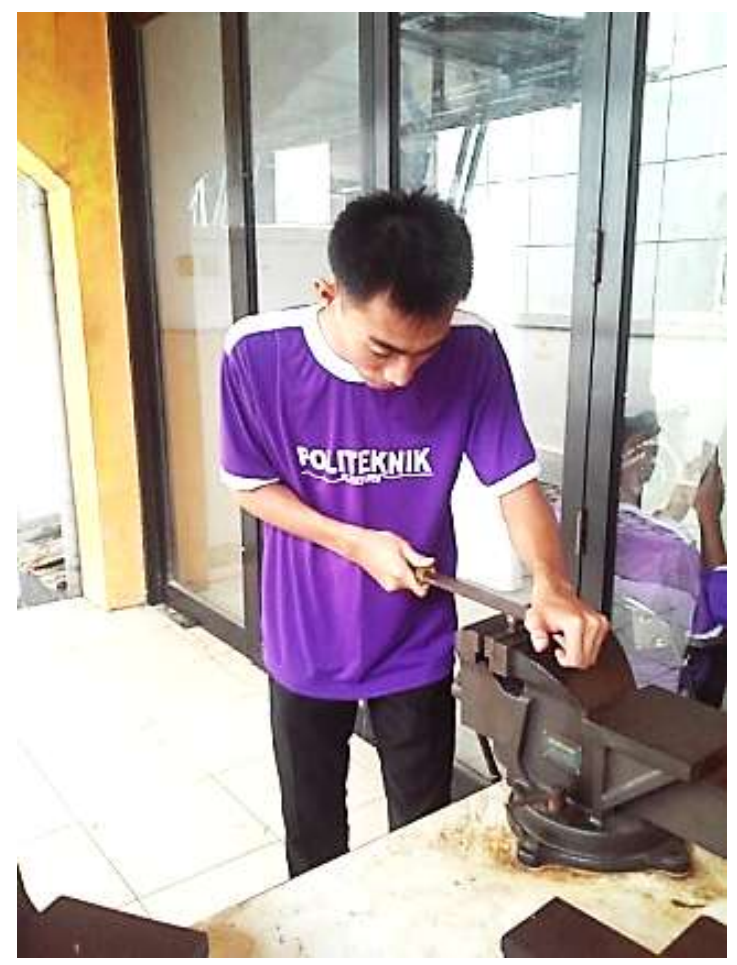

Gambar 2. Pembuatan Spesimen Uji

2. Perlakuan Panas pada dapur furnance

Spesimen yang telah dibuat tersebut selanjutnya diberi perlakuan panas. Sebelum spesimen diuji, harus dibersihkan terlebih dahulu dari kemungkinan korosi yang terjadi. Pembersihan tersebut cukup dilakukan dengan bantuan amplas kasar maupun halus agar tidak merusak struktur mikro spesimen.

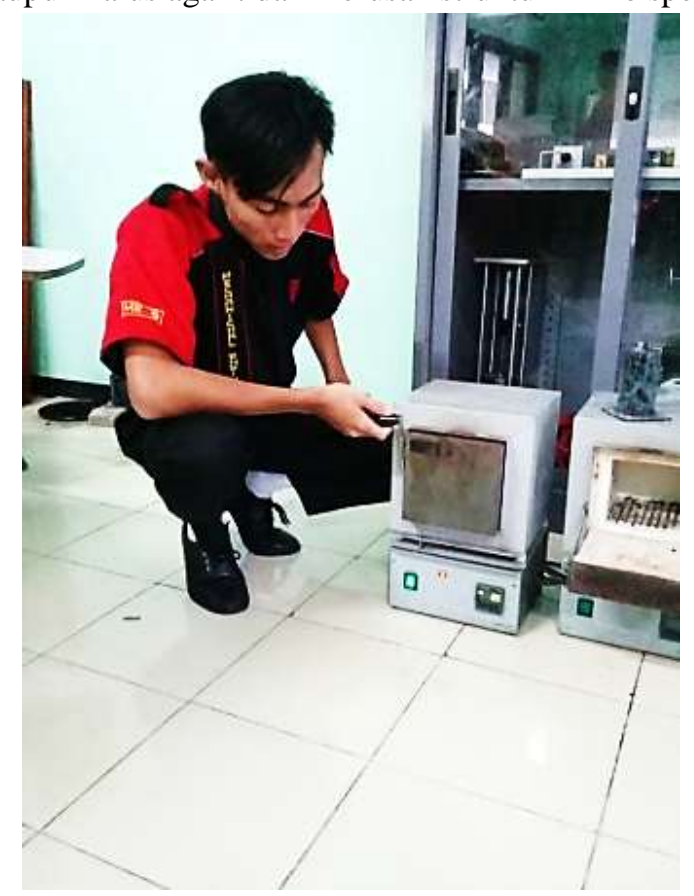

Gambar 3. Pemanasan Spesimen 
Jurnal Qua Teknika, Vol. 9 No. 1 Maret 2019

ISSN 2088-2424 (cetak); ISSN 2527-3892 (elektronik)

Fakultas Teknik Universitas Islam Balitar, Blitar

Https://ejournal.unisbablitar.ac.id/index.php/qua; Email: quateknika@unisbablitar.ac.id

Nila Nurlina. 2019. Pengaruh Pengujian Hardening pada Baja Karbon Rendah Sebagai Solusi Peningkatan Kualitas Material.

Jurnal Qua Teknika, (2019), 9(1) : 11-20

Perlakuan panas pada setiap spesimen dilakukan dengan suhu bervariasi untuk mendapatkan perbedaan sifat mekanik yang akan dihasilkan.

\section{Pendinginan}

Pendinginan hardening test pada penelitian ini dilakukan dengan air garam dan oli. Ketiga media pendingin tersebut akan memberikan sifat mekanik material yang berbeda-beda.

Tabel 1. Media Pendingin

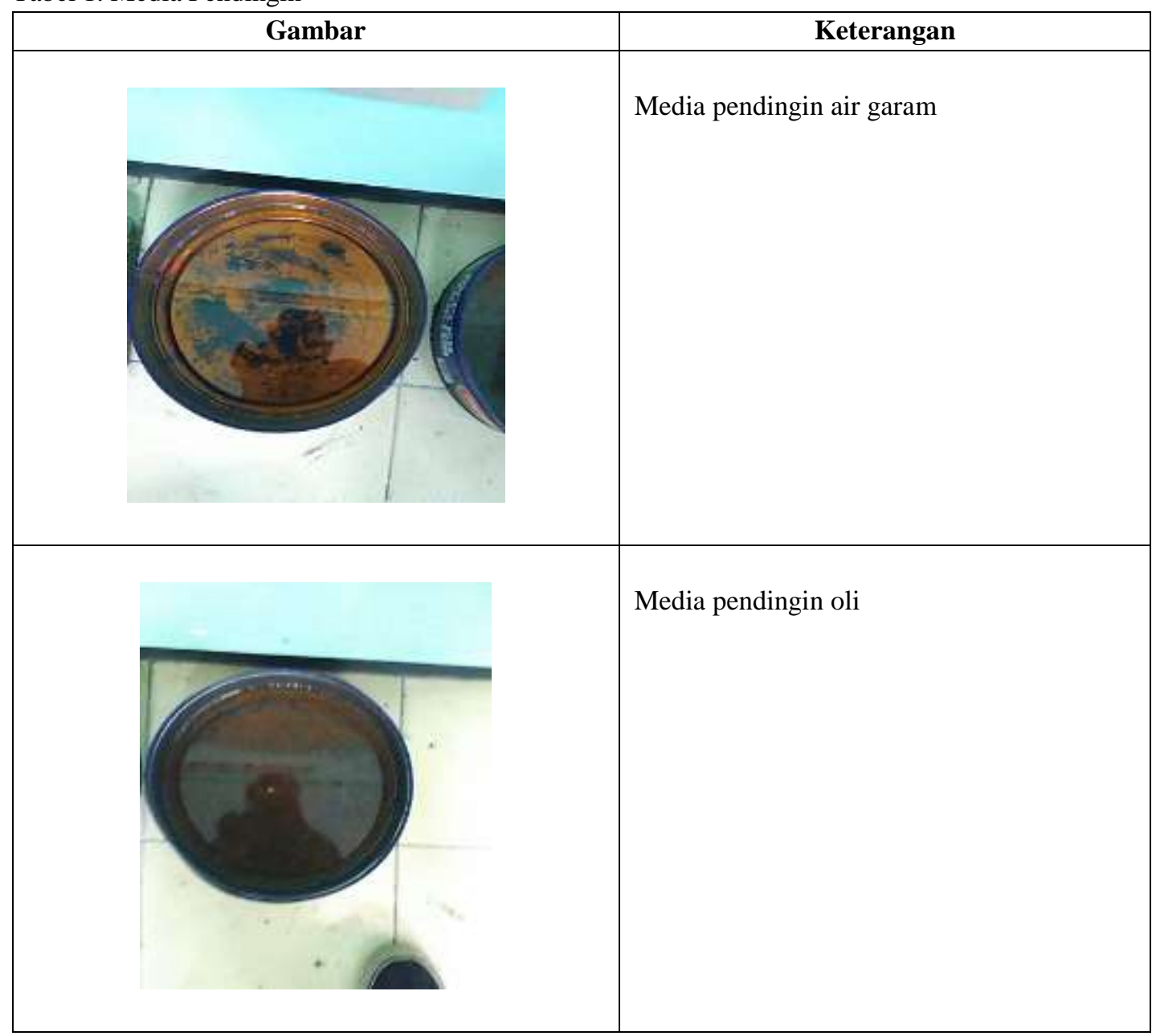

\section{Pembersihan Spesimen}

Setelah spesimen uji melalui proses pemanasan, penahanan suhu, serta pendinginan, selanjutnya spesimen tersebut dibersihkan ulang dengan menggunakan amplas baik halus maupun kasar. Hal tersebut bertujuan agar hasil dari pengujian sifat mekanik, khususnya kekerasan tidak dipengaruhi oleh unsur lain. Pembersihan material dilakukan karena setelah logam diberi perlakuan panas dalam dapur furnace dan selama pendinginan berlangsung, dimungkinkan akan menempel senyawa lain pada permukaan logam tersebut.

Pembersihan spesimen bertujuan untuk membersihkan spesimen uji dari unsur-unsur lain yang dapat mempengaruhi hasil pengujian. Pembersihan spesimen ini dilakukan hingga permukaan spesimen uji yang akan diberi titik penekanan pada saat pengujian kekerasan bersih dari unsur lain diluar komposisi material. 
Jurnal Qua Teknika, Vol. 9 No. 1 Maret 2019

ISSN 2088-2424 (cetak); ISSN 2527-3892 (elektronik)

Fakultas Teknik Universitas Islam Balitar, Blitar

Https://ejournal.unisbablitar.ac.id/index.php/qua; Email: quateknika@ unisbablitar.ac.id

Nila Nurlina. 2019. Pengaruh Pengujian Hardening pada Baja Karbon Rendah Sebagai Solusi Peningkatan Kualitas Material.

Jurnal Qua Teknika, (2019), 9(1) : 11-20

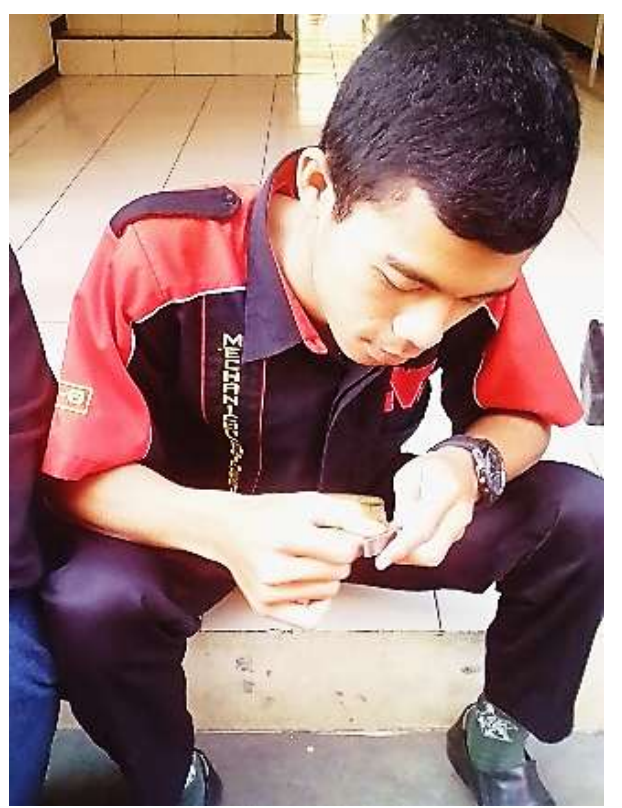

Gambar 4 Pembersihan Spesimen

\section{Pengujian Kekerasaran}

Pengujian sifat mekanik pada penelitian ini yaitu pertama dengan melakukan uji kekerasan (Hardness test). Pengujian tersebut menggunakan mesin vickers seperti terlihat pada gambar di bawah ini.

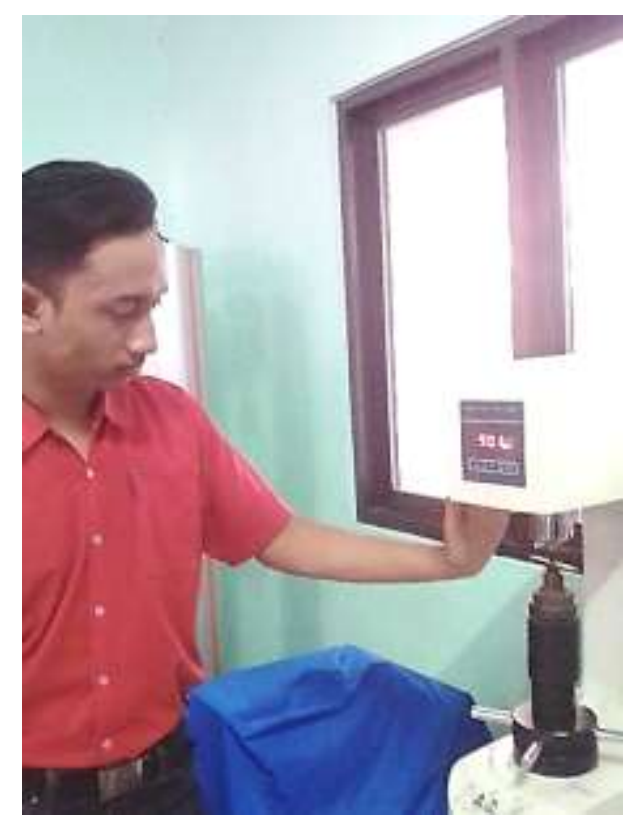

Gambar 5. Pengujian Kekerasan

Indentor baja yang digunakan dalam pengujian kekerasan dengan mesin rockwell adalah baja berbentuk kerucut intan. Spesimen uji diberi pembebaban sebesar $1000 \mathrm{~N}$ dengan loading time sekitar 15 detik. Hasil pengujian akan terdeteksi pada layar mesin. 
Jurnal Qua Teknika, Vol. 9 No. 1 Maret 2019

ISSN 2088-2424 (cetak); ISSN 2527-3892 (elektronik)

Fakultas Teknik Universitas Islam Balitar, Blitar

Https://ejournal.unisbablitar.ac.id/index.php/qua; Email: quateknika@unisbablitar.ac.id

Nila Nurlina. 2019. Pengaruh Pengujian Hardening pada Baja Karbon Rendah Sebagai Solusi Peningkatan Kualitas Material.

Jurnal Qua Teknika, (2019), 9(1) : 11-20

\section{HASIL DAN PEMBAHASAN}

Pada penelitian ini, pengujian dilakukan untuk mengetahui tingkat kekerasan dan ketangguhan baja karbon rendah dengan perlakuan hardening. Variabel yang digunakan dalam penelitian adalah variasi suhu dan media pendingin. Berikut disajikan skema variabel yang digunakan dalam pengujian normalizing pada penelitian ini.

Tabel 2. Variabel Pengujian

\begin{tabular}{|c|c|c|c|c|}
\hline No. & Perlakuan Panas & Quench & Suhu ${ }^{\mathbf{0}}$ & Holding \\
\hline 1 & Hardening & Oli & 700 & 15 menit \\
\hline 2 & Hardening & Air Garam & 700 & 15 menit \\
\hline 3 & Hardening & Oli & 820 & 15 menit \\
\hline 4 & Hardening & Air Garam & 820 & 15 menit \\
\hline 5 & Hardening & Oli & 850 & 15 menit \\
\hline 6 & Hardening & Air Garam & 850 & 15 menit \\
\hline 7 & Hardening & Oli & 880 & 15 menit \\
\hline 8 & Hardening & Air Garam & 880 & 15 menit \\
\hline
\end{tabular}

Berdasarkan tabel tersebut diketahui bahwa variabel penelitian yaitu suhu dan media pendingin. Suhu pada perlakuan ini dibuat secara bervariasi yaitu dari $700{ }^{0} \mathrm{C}$ hingga meningkat sampai dengan $880{ }^{0} \mathrm{C}$. Pengujian hardening ini memiliki waktu tahan selama 15 menit. Sementara variabel lainnya dalam penelitian ini yaitu media pendingin. Media pendingin yang digunakan dalam penelitian ini berupa oli dan air garam.

Tabel 3. Hasil Uji Kekerasan Media Pendingin Oli

\begin{tabular}{|c|c|c|c|}
\hline No & Quench & Suhu ${ }^{0} \mathrm{C}$ & Hasil Uji Kekerasan \\
\hline 1 & Oli & 700 & 42,5 \\
\hline 2 & Oli & 820 & 67,7 \\
\hline 3 & Oli & 850 & 75,2 \\
\hline 4 & Oli & 880 & 79,35 \\
\hline
\end{tabular}

Tabel 3. Hasil Uji Kekerasan Media Pendingin Oli didapatkan hasil bahwa peningkatan suhu mengakibatkan nilai kekerasan spesimen uji meningkat. Suhu yang digunakan dalam pengujian ini adalah suhu di atas titik kritis yaitu $700{ }^{\circ} \mathrm{C}, 820{ }^{\circ} \mathrm{C}, 850{ }^{\circ} \mathrm{C}$, dan $880{ }^{\circ} \mathrm{C}$ yang menghasilkan nilai kekerasan masing-masing sebesar 42,5; 67,7; 75,2; dan 79,35. Nilai kekerasan tertinggi terjadi ketika spesimen uji diberi perlakuan hardening pada suhu $880{ }^{\circ} \mathrm{C}$.

Tabel 4. Hasil Uji Kekerasan Media Pendingin Air Garam

\begin{tabular}{|c|c|c|c|}
\hline No & Quench & Suhu ${ }^{0} \mathrm{C}$ & Hasil Uji Kekerasan \\
\hline 1 & Air garam & 700 & 44,7 \\
\hline 2 & Air Garam & 820 & 68,6 \\
\hline 3 & Air Garam & 850 & 78,4 \\
\hline 4 & Air Garam & 880 & 82,15 \\
\hline
\end{tabular}

Tabel 4. Hasil Uji Kekerasan Media Pendingin Air Garam didapatkan hasil bahwa peningkatan suhu mengakibatkan nilai kekerasan spesimen uji meningkat. Suhu yang digunakan dalam pengujian ini adalah suhu di atas titik kritis yaitu $700{ }^{\circ} \mathrm{C}, 820{ }^{\circ} \mathrm{C}, 850{ }^{\circ} \mathrm{C}$, dan $880{ }^{\circ} \mathrm{C}$ yang menghasilkan nilai kekerasan masing-masing 
Jurnal Qua Teknika, Vol. 9 No. 1 Maret 2019

ISSN 2088-2424 (cetak); ISSN 2527-3892 (elektronik)

Fakultas Teknik Universitas Islam Balitar, Blitar

Https://ejournal.unisbablitar.ac.id/index.php/qua; Email: quateknika@unisbablitar.ac.id

Nila Nurlina. 2019. Pengaruh Pengujian Hardening pada Baja Karbon Rendah Sebagai Solusi Peningkatan Kualitas Material.

Jurnal Qua Teknika, (2019), 9(1) : 11-20

sebesar 42,7; 68,6; 78,4; dan 82,15. Nilai kekerasan tertinggi terjadi ketika spesimen uji diberi perlakuan hardening pada suhu $8800^{\circ} \mathrm{C}$.

Berdasarkan tabel 3 dan 4 di atas, nilai kekerasan hasil perlakuan hardening didapatkan bahwa media pendingin air garam mampu membuat struktur spesimen uji lebih keras dibandingkan dengan oli. Dengan kata lain, media pendinginan mempengaruhi tingkat kekerasan. Pendinginan cepat memberikan tingkat kekerasan lebih besar daripada pendinginan lambat.

\section{SIMPULAN}

Berdasarkan hasil penelitian yang telah dilakukan, didapatkan kesimpulan sebagai berikut:

1. Suhu yang digunakan dalam pengujian ini adalah suhu di atas titik kritis yaitu $700{ }^{\circ} \mathrm{C}, 820{ }^{\circ} \mathrm{C}, 850{ }^{\circ} \mathrm{C}$, dan $8800^{\circ} \mathrm{C}$.

2. Nilai kekerasan tertinggi pada hasil perlakuan hardening dengan media pendingin oli yaitu pada suhu $880{ }^{\circ} \mathrm{C}$ dengan nilai kekerasan sebesar 79,35 .

3. Nilai kekerasan tertinggi pada hasil perlakuan hardening dengan media pendingin oli yaitu pada suhu $880{ }^{\circ} \mathrm{C}$ dengan nilai kekerasan sebesar 82,15 .

Saran untuk penelitian selanjutnya adalah sebagai berikut:

1. Waktu dan temperatur setiap material perlu dibuat lebih bervariasi lagi

2. Holding time harus dilakukan dalam rentang waktu yang tepat

3. Sebelum digunakan, alat harus dikalibrasi terlebih dahulu agar hasil sesuai dengan standar.

\section{REFERENSI}

Anyalebechi, P.N. 1995. "Analysis of The Effect of Alloying Element Hydrogen Solubility in Liquid Alumunium Alloys", Scripta Mekllurgica et Materialia, Vol 33/ No.8.

ASM Metals Handbook. (2005), "Vol 09 : Metallography and Microstruc-tures”, ASM International.

ASTM E3-96, Standard Practice for Preparation of Metallographic Spesimens.

ASTM Handbook E18, Standard Test Methods for Rockwell Hardness and Rockwell Superficial Hardness of Metallic Materials.

Callister Jr. W.D. 2004. Materials Science and Engineering: An Introduction, 6th Edition. John Wiley and Sons, Inc.

Callister Jr.,W.D., 2000, "Fundamentals of Materials Science and Engineering", Fifth Edition. Text, John Wiley \& Sons, Inc.

Cardarelli, Francois. 2000. Material Handbook A Concise Desktop Reference. New York: Springer.

Dieter, G.E., 1996, "Metalurgi Mekanik", Jakarta: Erlangga.

Lontolawa, Steven D.O. 2016. Analisa Penyebab Kerusakan Differential Pada Unit Dump Truck Quon di PT.

United Tractor Site Rantau. Balikpapan: Politeknik Negeri Balikpapan.

Normalizing. Jurnal Pendidikan Profesional Volume 5 No.2, (Agustus 2016):9-18

Nukman, Harjono. 2014. Pengaruh Pross Perlakuan Panas Normalixing Dan Quenching Dengan Media Air dan Minyak Silikon Terhadap Sifat Mekanik Dan Struktur Mikro Pada Baja Karbon Medium. Majalah Ilmiah Sriwijaya Volume XXV No.18 (April 2014): 44-54

Oestwald, P.F.,and Munoz, J., 1996, "Manufacturing Processes and Systems", Canada: John Wiley \& Sons.

R. Kohar, Madagaskar. 2014. Pengaruh Perbedaan Kedalaman Potongan Pada Proses Bubut Dan Perlakuan

Panas Normalizing Terhadap Perubahan Sifat Mekanik Baja Karbon Menengah. Jurnal Desiminasi Teknologi Volume 2 No.1, (Januari2014): 60-64

Smallman, R.E., Metalurgi Fisik Modern dan Rekayasan Material, Penerbit Erlangga, Jakarta, 1999

Suratman, Rochim. 1994. Panduan Prrogram Perlakuan Panas. Bandung: Lembaga Penelitian Institusi Teknologi Bandung

Surdia,Tata., Saito, Shinroku. 1999. Pengetahuan Bahan Teknik. Jakarta: Pradnya Paramita. 
Jurnal Qua Teknika, Vol. 9 No. 1 Maret 2019

ISSN 2088-2424 (cetak); ISSN 2527-3892 (elektronik)

Fakultas Teknik Universitas Islam Balitar, Blitar

Https://ejournal.unisbablitar.ac.id/index.php/qua; Email: quateknika@unisbablitar.ac.id

Nila Nurlina. 2019. Pengaruh Pengujian Hardening pada Baja Karbon Rendah Sebagai Solusi Peningkatan Kualitas Material.

Jurnal Qua Teknika, (2019), 9(1) : 11-20

United Tractors. 2008. Basic Mechanic Course 1: Axle, Suspension and Wheel . Jakarta: Yayasan Karya Bakti PT.United Tractors, Tbk.

Zulkifli. 2014. Modul Pembelajaran Lab Pengujian Mesin : Teknik Mesin Alat Berat,Polteknik Negeri Balikpapan 